\title{
Six minute walk test in Italian children with cystic fibrosis aged 6 and 11
}

\author{
Diletta Innocenti ${ }^{1}$, Eleonora Masi ${ }^{1}$, Giovanni Taccetti ${ }^{2}$, Marco Genito ${ }^{1}$, Elena Balestri ${ }^{3}$, Anna Rita Berghelli ${ }^{4}$, \\ Maria Antonietta Ciciretti ${ }^{5}$, Francesca Collini ${ }^{6}$, Patrizia Fanzaghi ${ }^{7}$, Annalisa Fogazzi ${ }^{8}$, Paola Leone ${ }^{9}$, \\ Riccardo Guarise ${ }^{10}$ \\ ${ }^{1}$ Rehabilitation Unit, Anna Meyer Children's University Hospital, Florence; ${ }^{2}$ Cystic Fibrosis Centre, Anna Meyer \\ Children's University Hospital, Florence; ${ }^{3}$ Cystic Fibrosis Centre, Maurizio Bufalini Hospital, Cesena; ${ }^{4}$ Respiratory \\ Rehabilitation Department, Regina Margherita Children's University Hospital, Turin; ${ }^{5}$ Cystic Fibrosis Centre, Giuseppe \\ Tatarella Hospital, Cerignola; ${ }^{6}$ Cystic Fibrosis Centre, San Liberatore di Atri Hospital, Atri; ${ }^{7}$ Cystic Fibrosis Centre, \\ Parma University Hospital, Parma; ${ }^{8}$ Cystic Fibrosis Centre, Spedali Civili, Brescia; ${ }^{9}$ Pediatric Department, Bambino \\ Gesù Children's Hospital, Rome; ${ }^{10}$ Cystic Fibrosis Centre, Civile Maggiore Hospital, Verona, Italy
}

\author{
Correspondence: Diletta Innocenti, Rehabilitation Unit, Anna Meyer \\ Children's University Hospital, Anna Meyer Children's University \\ Hospital, Viale Pieraccini 24, 50139 Florence, Italy. \\ Tel. +39. 055.5662568 - Fax: +39.055.5662474. \\ E-mail: diletta.innocenti@meyer.it
}

Key words: 6 minute walk test; cystic fibrosis; physical activity; exercise, paediatrics.

Conflict of interest: The authors declare that they have no competing interests, and all authors confirm accuracy.

Funding: This research did not receive any specific grant from funding agencies in the public, commercial, or not-for-profit sectors.

Ethics approval: The study was approved by the Pediatric Ethics Committee of Meyer Children's Hospital of Florence, and by all the other Ethics Committees of the Centers that took part in the study. Parents or legal guardians gave written informed consent for all enrolled children

Acknowledgments: The authors would like to thank the respiratory physiotherapist team of Physical medicine and rehabilitation department and the interdisciplinary team of the Cystic Fibrosis Center of Meyer Children's Hospital. We also thank all our little patients who have given their contribution.

Received for publication: 21 June 2021.

Accepted for publication: 17 December 2021.

Publisher's note: All claims expressed in this article are solely those of the authors and do not necessarily represent those of their affiliated organizations, or those of the publisher, the editors and the reviewers. Any product that may be evaluated in this article or claim that may be made by its manufacturer is not guaranteed or endorsed by the publisher.

${ }^{\circ}$ Copyright: the Author(s), 2021

Licensee PAGEPress, Italy

Monaldi Archives for Chest Disease 2022; 92:2047

doi: 10.4081/monaldi.2021.2047

This article is distributed under the terms of the Creative Commons Attribution-NonCommercial International License (CC BY-NC 4.0) which permits any noncommercial use, distribution, and reproduction in any medium, provided the original author(s) and source are credited.

\begin{abstract}
Six minute walk test (6MWT) is a field exercise test widely used in clinical practice, both in adults and in pediatric patients. The primary aim of the study is to evaluate the physical performance of the subjects and compare them with the predicted Italian values. The secondary aim is to verify the possible relationship between the 6MWT distance (6MWD) and the clinical variables of the sample. Italian children between 6-11 years affected by $\mathrm{CF}$ were recruited from 9 regional centers for $\mathrm{CF}$. Short questionnaire assessments about their health state and physical activity routine was administered. Anthropometric characteristics were measured before the test and, peripheral oxygen saturation $\left(\mathrm{SpO}_{2}\right)$, heart and respiratory rate were measured before and after a 6-minute walk test. The tests were performed according to the American Thoracic Society (ATS) guidelines. 6MWD was compared with the predicted distance calculated by the reference equation for healthy subjects of the same age. A total of 132 children were recruited (70 male) and completed the assessment. The mean $( \pm \mathrm{SD})$ for $6 \mathrm{MWD}$ was $557.4( \pm 69.9)$, male $=551.4( \pm 80.0)$, female $=560.4( \pm 63.3)$, however the predicted distance mean was $605 \mathrm{~m}$. A total of 101(76.5\%) subjects practice regular physical activity. A total of $31(23 \%)$ had a $\mathrm{FEV}_{1}$ lower than their lower limits of normal (LLN). Functional performance on the 6MWT was poorer among the CF patients than among the predicted distance estimated with Italian values. The correlation with the amount of physical activity and 6MWD has been verified.
\end{abstract}

Contributions: DI, conceptualization (lead); writing - original draft (lead); writing review and editing (equal); methodology (supporting); investigation (equal); resources (equal); EM, writing review and editing (equal); data curation (equal); methodology (supporting); resources (equal); investigation (equal); GT, writing review and editing (equal); supervision (equal); $M G$, data curation (equal); resources (equal); investigation (equal); software (equal); EB, resources (supporting); investigation (supporting); ARB, MAC, FC, PF, AF, PL, resources (supporting); investigation (supporting); RG, formal analysis (lead); methodology (lead); writing review and editing (equal); supervision (equal); software (equal). All the authors read and approved the final version of the manuscript and agreed to be accountable for all aspects of the work. 


\section{Introduction}

Cystic fibrosis (CF) is a chronic genetic disorder associated with deterioration of lung function, malnutrition, and progressive exercise intolerance [1]. Some studies have shown that patients with $\mathrm{CF}$ have decreased respiratory and peripheral muscle strength than healthy peers [1-3]. Many factors as nutritional status, hypoxia, inactivity and corticosteroid treatments affect skeletal muscle in CF patients [4]. The decrease in muscle strength, nutritional deficiencies and the decline in lung function may decrease exercise tolerance and determinate fatigue during daily life activities [1-4]. Several studies have shown that exercise capacity in patients with CF is related to mortality [5-6].

Exercise capacity can be evaluated in different ways: some tests provide an almost complete evaluation of all the systems involved during physical performance, others provide only basic information but are easier and cheaper to carry out [7]. The six minutes walk test (6MWT) is a sub-maximal field test, inexpensive, easy to administer and well tolerated and there is a strong indication that the 6MWT is a reproducible test to assess the functional capacity of children and adolescents with CF [8-12]. To better explain the test result, reference values are needed from the healthy population of the same age, ethnicity, gender, height and weight [9]. The comparison between the measured value and the predicted value allows to quantify the possible degree of impairment of physical performance. Pereira et al. [9] have shown that functional capacity measured with 6MWT is reduced in subjects with CF in the age group 8-16 years compared to the control group of the same age. For the healthy European population there were four studies published [13-16]. In particular, Vandoni et al. proposes an equation for the calculation of the 6MWT predicted distance for Italian children aged 6 to 11 years [13].

The primary aim of this study is to assess the physical performance of Italian children affected by CF aged 6-11 years and the secondary aim is to verify the possible correlation between the 6MWT distance (6MWD) and the clinical variables of the sample, in particular respiratory function.

The primary outcomes were verified using the equation proposed by Vandoni because the socio-cultural characteristics of the sample are similar to the study population. The data were also compared with the equations proposed by Urlich and Lammers as they are most frequently used as a reference for the European population.

\section{Materials and Methods}

\section{Participants}

A total of 132 subjects were recruited from 9 CF regional centers. Enrollment was carried out by selecting the subjects regularly attending the CF centers from October 2016 to March 2018.

Children with confirmed CF diagnosis [17] aged 6-11 years were included in the study. The exclusion criteria were: pulmonary exacerbation within the 15 days before the test; neurological, metabolic, orthopedic or cardiovascular associated diseases; behavioral and cognitive deficits; absolute contraindications to 6MWT; longterm oxygen therapy.

The study was approved by the Pediatric Ethics Committee of Meyer Children's Hospital of Florence, and by all the other Ethics Committees of the centers that took part in the study. Parents or legal guardians gave written informed consent for all enrolled children. All the procedures used complied with the principles of the Declaration of Helsinki.

\section{Methods}

The 6MWT were performed according to the American Thoracic Society (ATS) guidelines [18] and conducted by trained physiotherapists. Each child performed the test once and was instructed to walk as fast as possible without running or jogging and was allowed to stop whenever they wanted. Researchers encouraged the participants with standardized phrases, as described by ATS [18]. The tests were conducted in flat, straight corridors with a hard surface with a length between 20 and 30 meters depending on the setting availability. The children walked at a self-selected pace along the path.

Anthropometric data (age, height, weight, body mass index); type of genotype mutation, microbiological status [based on European Cystic Fibrosis Society (ECFS) criteria] [19]; pancreatic status (based on enzyme usage); CF related diabetes (based on the use of insulin) use of CFTR (cystic fibrosis transmembrane conductance regulator) modulators; habitual inhalation therapies; home physiotherapy program and the amount of sport were collected from medical records at the day of the test.

Pulmonary function status was recorded by forced expiratory volume in the first second $\left(\mathrm{FEV}_{1}\right)$, forced vital capacity $(\mathrm{FVC})$ measured in liters and lower limit of normal (LLN) - measured using global lung function [20]. Severity of lung disease was assessed according to Flume 2007 [21]. The days of hospitalization and the number of intravenous antibiotic treatments in the last 12 months were also collected. Heart rate (HR), respiratory rate (RR), peripheral oxygen saturation $\left(\mathrm{SpO}_{2}\right)$ were recorded at baseline during a 10-min rest period and soon after the end of 6MWT. The subjective sensation of dyspnea and muscular fatigue were measured using a visual analogue scale (VAS) [14].

\section{Statistical analysis}

Descriptive statistics of anthropometrics were presented according to nature of data as means (standard deviation) or frequencies (percentage) or median (interquartile range). Shapiro-Wilk test was used to verify the normality of distribution of all variables. Differences in means or medians among gender in anthropometrics and lung function were assessed by using unpaired $t$-test, or MannWhitney test according to distributions previously tested.

Unpaired $t$-tests with Welch's approximation and Pearson correlation coefficients were computed to assess significant differences and correlations between 6MWT distance and age, sex, lung function, physical activity, inhaled drug therapy, type of CFTR mutation, diabetes presence, type and regimen of airway clearance techniques. One-way ANOVA and Kruskall-Wallis tests were used to compare parameters with more than two groups according to nature of data. Post-hoc tests were adjusted by Bonferroni correction to reduce the risk of type I error. Predicted measure of 6MWT distance were derived by applying equation from previous studies: Vandoni et al. [13], Geiger et al. [14] and Ulrich et al. [16]. To assess the agreement between the measured 6MWT distance and the predicted values by each prediction equation, we plotted the difference between the 2 measurements (i.e., predicted and measured 6MWT distance) against the mean of the 2 measurements as described by Bland and Altman. A $p<0.05$ was considered statistically significant.

\section{Results}

A total of 132 children were recruited (70 male) and completed the assessment. Participant mean age $( \pm \mathrm{SD})$ was $8.7( \pm 1.6)$ years 
Table 1. Clinical characteristics of the sample.

\begin{tabular}{|c|c|c|c|}
\hline $\mathrm{FEV}_{1}$ in liters (SD) & & $1.6(0.5)$ & 0 \\
\hline FVC in liters (SD) & & $1.9(0.6)$ & 0 \\
\hline $\mathrm{FEV}_{1}<\mathrm{LLN}^{\circ}$ & & $31(23)$ & 0 \\
\hline Genotype & $\begin{array}{l}\text { F508 del homozygous } \\
\text { F508 del heterozygous } \\
\text { Other }\end{array}$ & $\begin{array}{l}32(24.24) \\
54(40.9) \\
40(30.3)\end{array}$ & 6 \\
\hline Pancreatic insufficienc & & $87(66)$ & 3 \\
\hline CF-related diabetes $^{\circ}$ & & $1(0.75)$ & 7 \\
\hline Diagnosed by ${ }^{\circ}$ & $\begin{array}{l}\text { Screening } \\
\text { Meconium ileus } \\
\text { Symptoms }\end{array}$ & $\begin{array}{l}77(58) \\
15(11) \\
39(29)\end{array}$ & 2 \\
\hline Chronic colonization $^{\circ}$ & $\begin{array}{l}\text { Pseudomonas aeruginosa } \\
\text { Staphylococcus aureus methicillin-susceptible } \\
\text { other pathogens }\end{array}$ & $\begin{array}{l}20(15) \\
78(59) \\
30(23)\end{array}$ & 2 \\
\hline Hospitalized in the last & 12 months $^{\circ}$ & $37(28)$ & 6 \\
\hline Intravenous antibiotic & therapy in the last 12 months ${ }^{\circ}$ & $35(27)$ & 6 \\
\hline CFTR modulator $^{\circ}$ & & 0 & 6 \\
\hline Inhalation therapy ${ }^{\circ}$ & $\begin{array}{l}\text { Mucolytic } \\
\text { Antibiotic } \\
\text { Short-acting bronchodilator } \\
\text { Long-acting bronchodilator } \\
\text { Inhaled corticosteroid }\end{array}$ & $\begin{array}{l}81(61) \\
21(16) \\
52(39) \\
18(14) \\
12(9)\end{array}$ & 6 \\
\hline Airway clearance techn & iiques $^{\circ}$ & $127(97)$ & 0 \\
\hline
\end{tabular}

$\mathrm{FEV}_{1}$, forced expiratory volume in the first second; FVC, forced vital capacity; LLN, lower limit of normal; ${ }^{\circ}$ data shown as number and percentage (\%).

Table 2. Anthropometric, clinical characteristics and variables measured in the test.

\begin{tabular}{|c|c|c|c|}
\hline & Male $(n=70)$ & Female $(n=62)$ & Total $(\mathrm{n}=132)$ \\
\hline Age (years)* & $8.7(1.6)$ & $8.7(1.6)$ & $8.7(1.6)$ \\
\hline Height $(\mathrm{cm})^{*}$ & $131.6(11.5)$ & $130.4(11.9)$ & $131(11.7)$ \\
\hline Weight $(\mathrm{kg})^{*}$ & $30.1(8.9)$ & $29.8(16.1)$ & $29.9(12.8)$ \\
\hline BMI $\left(\mathrm{kg} / \mathrm{m}^{2}\right)^{*}$ & $16.9(2.4)$ & $16.1(2.1)$ & $16.6(2.3)$ \\
\hline BMI $<10^{\text {th }}$ centile & $9(12,8)$ & $6(9.7)$ & $15(11,4)$ \\
\hline 6MWT distance $(\mathrm{m})^{*}$ & $551.4(80.0)$ & $560.4(63.3)$ & $557.4(69.9)$ \\
\hline Pre HR (bpm)* & $94.8(12.5)$ & $97.8(12.9)$ & $96.2(12.7)$ \\
\hline Post HR (bpm)* & $133(20.2)$ & $126.9(22)$ & $130.2(21.2)$ \\
\hline Pre $\mathrm{SpO}_{2}{ }^{*}$ & $98.3(1.3)$ & $97.9(1.4)$ & $98.1(1.4)$ \\
\hline Post $\mathrm{SpO}_{2}{ }^{*}$ & $97.8(1.4)$ & $97.9(1.7)$ & $97.8(1.6)$ \\
\hline Pre RR (breaths/min)* & $22.6(4.6)$ & $22.0(4.5)$ & $22.3(4.6)$ \\
\hline Post RR (breaths/min)* & $30.5(6.2)$ & $30.6(6.7)$ & $30.6(6.4)$ \\
\hline Pre dyspnea $(\mathrm{VAS})^{\circ}$ & $0(0.5)$ & $0(0)$ & $0(0.5)$ \\
\hline Post dyspnea (VAS) ${ }^{\circ}$ & $2(4.5)$ & $2(2.5)$ & $2(3.5)$ \\
\hline Pre fatigue $(V A S)^{\circ}$ & $0(1)$ & $0(0)$ & $0(0.5)$ \\
\hline Post fatigue $(V A S)^{\circ}$ & $3(5.5)$ & $2(4.5)$ & $2.5(5.5)$ \\
\hline Sport $0^{\#}$ & $13(18.6)$ & $10(16.1)$ & $23(17.5)$ \\
\hline Sport $1^{\#}$ & $4(5.7)$ & $4(6.5)$ & $8(6.0)$ \\
\hline Sport $2^{\#}$ & $44(62.9)$ & $41(66.1)$ & $85(64.5)$ \\
\hline Sport $3^{\#}$ & $5(7.1)$ & $3(4.8)$ & $8(6.0)$ \\
\hline Sport $^{\#}$ & $4(5.7)$ & $4(6.5)$ & $8(6.0)$ \\
\hline
\end{tabular}

BMI, body mass index; 6MWT, six minutes walk test; HR, heart rate; RR, respiratory rate; VAS, visual analogue scale; *data shown as mean and SD; ${ }^{\circ}$ data shown as median and interquartile range; ${ }^{\text {data }}$ shown as number and percentage; Sport 0, no sports; Sport 1, $\leq 2$ hours/week; Sport 2, from 2 to 4 hours/week; Sport 3, $\geq 4$ hours/week; Sport M, missed data. 
old, weight was $29.9( \pm 12.8) \mathrm{kg}$, height $131( \pm 11.7) \mathrm{cm}$ and BMI of $16.6( \pm 2.3)$. The baseline and clinical characteristics of study population are summarized in Tables 1 and 2.

All participants completed the 6MWT and no subject needed pauses or interruptions during the test. No desaturations were found in the studied sample with a mean $\mathrm{SpO}_{2}$ at the end of the test: $97.8 \%$ (93-100). The mean $6 \mathrm{MWT}( \pm \mathrm{SD})$ distance was $557.4 \pm 70$ ) with range of 324-705 meters. The mean 6MWT distance among males was $551.4( \pm 80)$ with range of 324-705 and among females $560.4( \pm 63.3)$ with range of $395-663$. During the tests there were no episodes of desaturation. The mean lower $\mathrm{SpO}_{2}( \pm \mathrm{SD})$ was $97.8 \%( \pm 1.6)$ with a range of $93-100$. Table 2 shows 6 MWT measures. There is no statistically significant difference in the meters walked between males and females $(p=0.6391)$. Moreover, there are no statistically significant proportion differences for microbiological status ( $\mathrm{p}=0.7051)$, use of antibiotics in the last 12 months $(\mathrm{p}=0.3858)$, days of hospitalization in the last 12 months $(\mathrm{p}=0.2710$ ), use of inhaled drugs ( $\mathrm{p}$ from 0,4710 to 0,9443 ) and type or regimen of airway clearance techniques $(\mathrm{p}=0.9685)$. There is a statistically significant difference in 6MWT distance between those who practice less than 2 hours a week of sport and those who practice at least $4(\mathrm{p}=0.02)$ and also between those who practice sport and those who do not $(\mathrm{p}=0.007)$ as shown in Figure 1A. The final heart rate of subjects that practice two or more hours of physical activity is significantly lower than those who do not $(\mathrm{p}<0.009)$, and also between those who practice less than 4 hours and who practice more than 4 hours $(\mathrm{p}<0.003$ ) (Figure 1B). Moreover, the final heart rate mean is statistically significant greater in males than females $(\mathrm{p}<0.05)$.

The distance walked from the sample $(557.4 \mathrm{~m})$ is significantly less than the predicted distance calculated with the reference equation for healthy subjects of the same age (Figure 2). 6MWD mean calculated with Vandoni et al.'s reference equation was of 605.1 (49.5), 6MWD mean calculated with Ulrich et al.'s reference equation was of 583.4 (28.5) and 6MWD mean calculated with Geiger et al.'s reference equation was of 607.6 (39.8). A number of 31 subjects who have a $\mathrm{FEV}_{1}$ below than their lower limit of normal (LLN) [21], walked a greater distance [mean 6MWD 549.8 (74.3) $\mathrm{m}$ ] than those with a normal $\mathrm{FEV}_{1}$ [mean 6MWD 583 (44.4) m] $\mathrm{p}=0.003$. Moreover, those who practice sports have mean $\mathrm{FEV}_{1} \%$ pred lower $90.4 \%$ (2) than those who do not $101 \%$ (3.4) and this is statistically significant at $\mathrm{p}=0.001$. Subjects with $\mathrm{FEV}_{1} \%$ pred lower $90 \%$ practice more sports activities than those with a higher $\mathrm{FEV}_{1}(\mathrm{p}<0.001)$.

Figure $3 \mathrm{~A}$ shows the predicted 6MWT distance from the observed distance. In the Bland-Altman plots (Figure 3B), linear regression analysis revealed a weak but significant downward trend of the difference between the predicted and measured 6MWT distance. All predictive models tend to overestimate performances underlined by dots outside superior limits of agreement. Dispersion tends to be higher in all prediction models reported but it becomes wider in Vandoni and Geiger whilst seems to remain stable in Ulrich equation. The $95 \%$ limits of agreement were small-

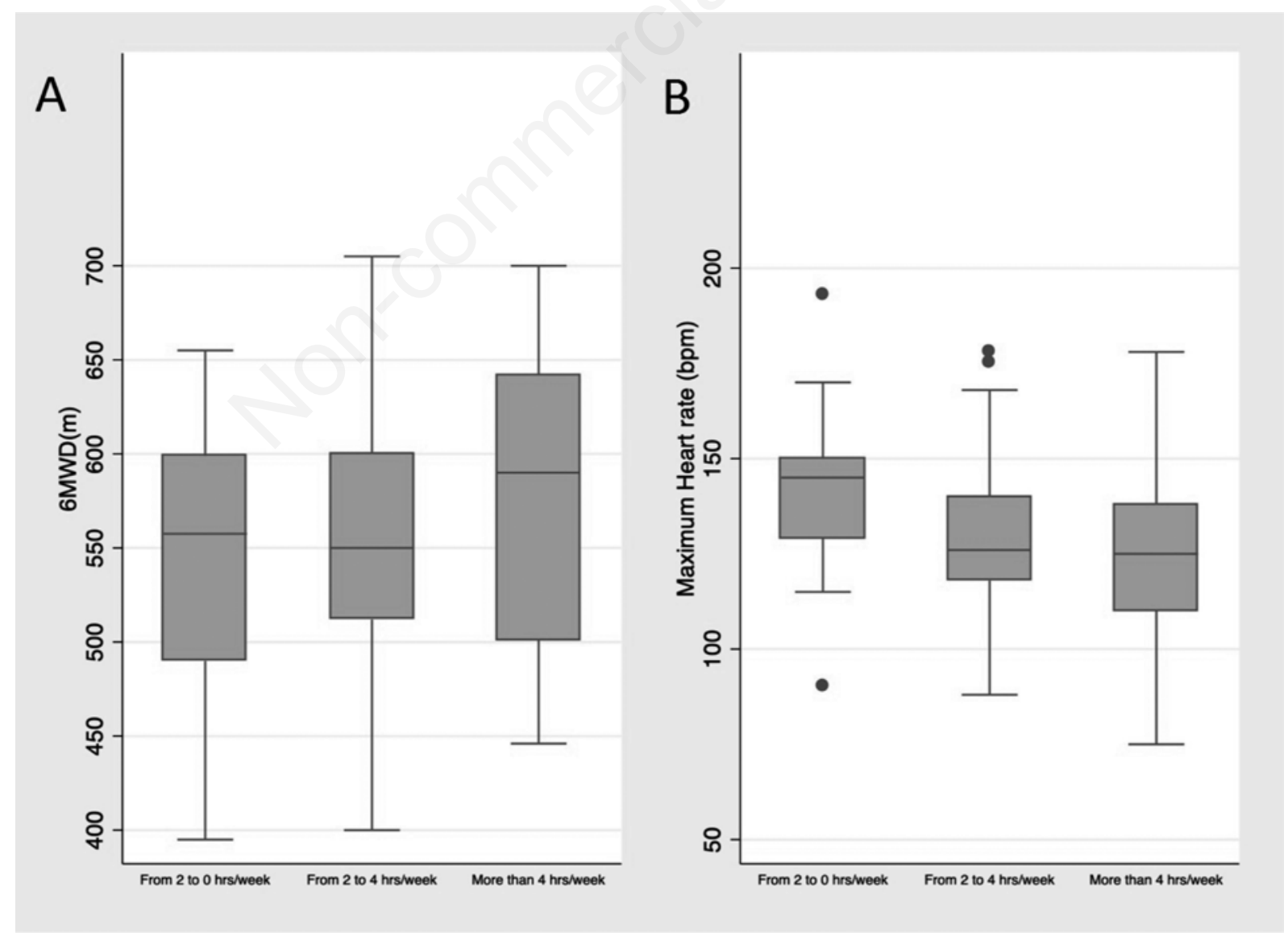

Figure 1. Boxplot of mean 6MWD (A) and mean maximum heart rate (B) stratified by week frequency of physical activity. 


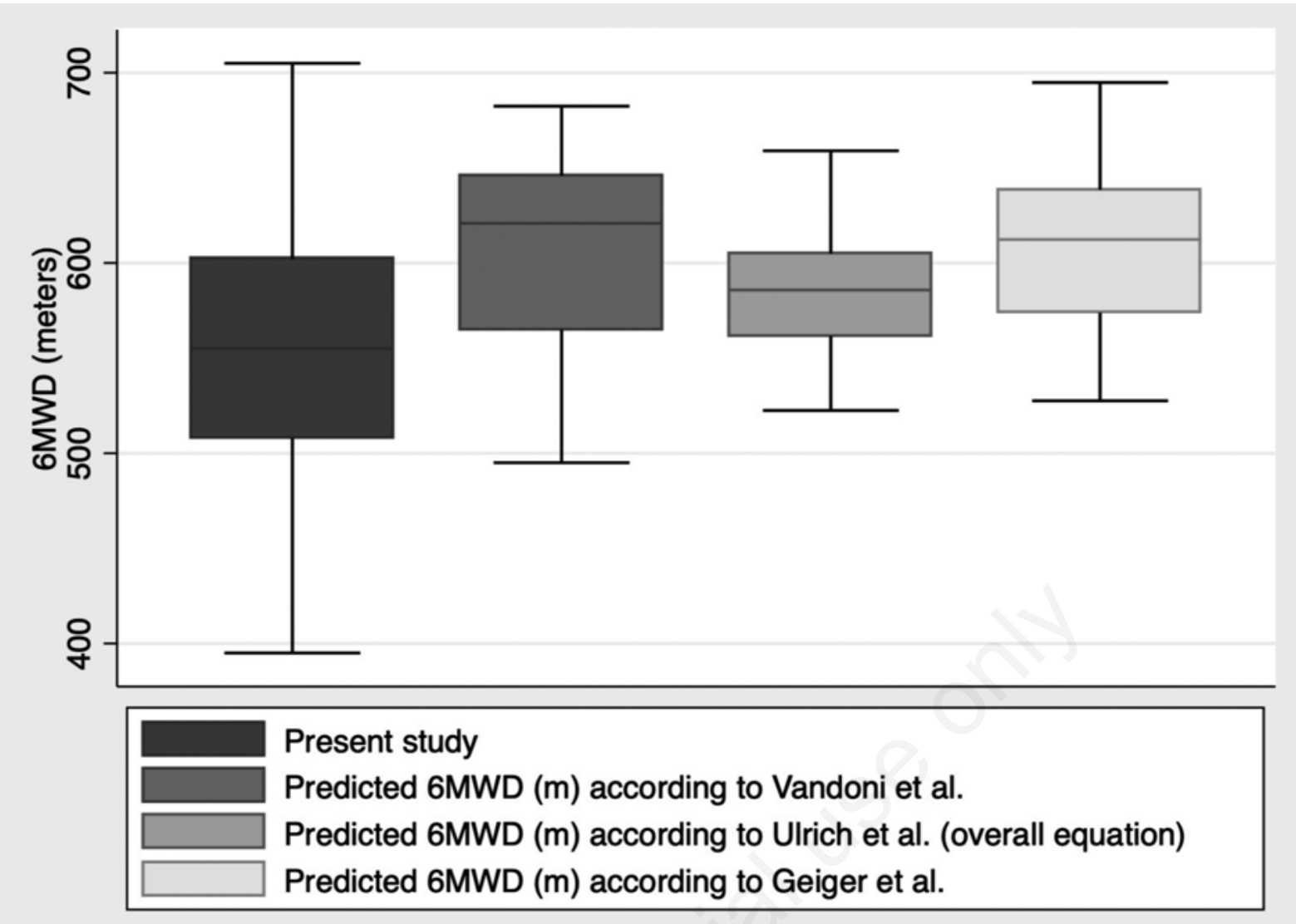

Figure 2. Boxplots of mean 6MWD. Boxplots of mean 6MWD (from left to right, first box) compared with predicted values of 6MWD according to Vandoni et al. [13] (second box), Ulrich et al. [16] (third box) and Geiger et al. [14] (fourth box).
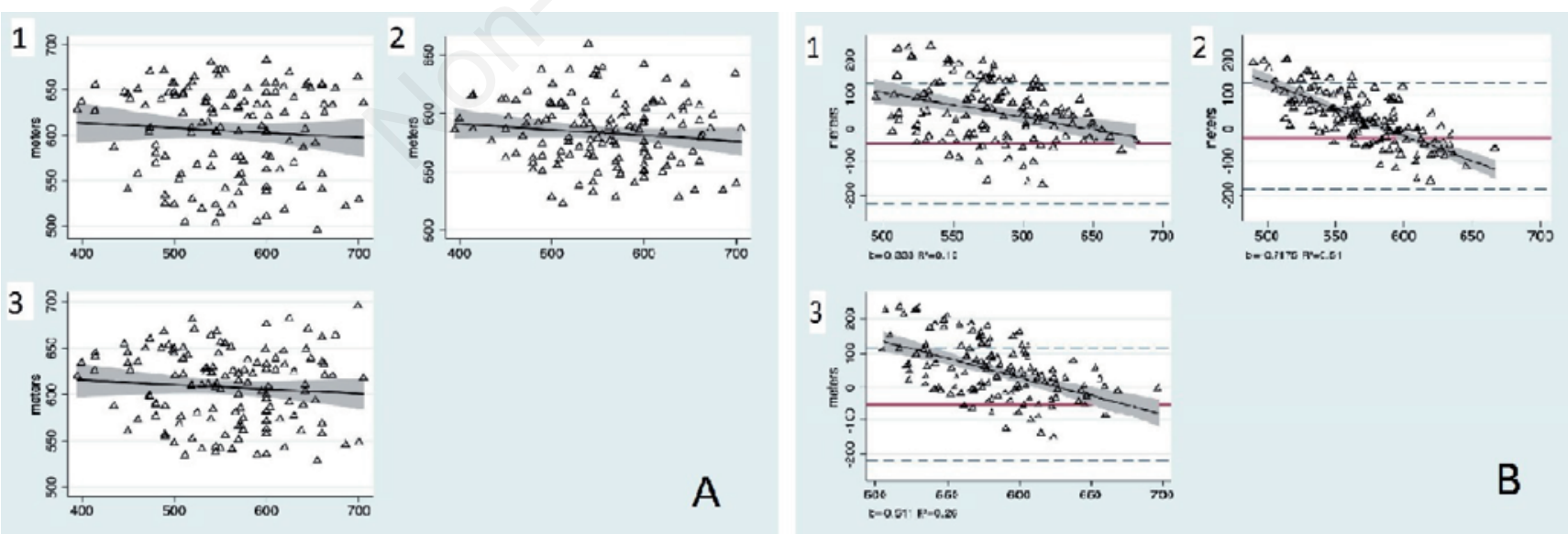

B

Figure 3. Predicted versus observed 6MWT distance. A. Predicted (y-axis) versus observed (x-axis) 6MWT distance (meters) according to Vandoni et al. (Figure A1) and Ulrich et al. overall equation (Figure A2), Geiger et al. (Figure A3). Grey area corresponds to 95\% confidence interval and line corresponds to fitted values. B. Bland-Altman plots of agreement between observed 6MWT distance (m) and predicted values according to Vandoni et al. (Figure B1), Ulrich et al. overall equation (Figure B2), Geiger et al. (Figure B3). Grey area corresponds to $\mathbf{9 5 \%}$ confidence interval, continue line corresponds to the line of best fit from linear regression and broken lines represent limits of agreement, solid horizontal line corresponds to mean difference; $b$, unstandardized regression coefficient; $R^{2}$, coefficient of determination of linear regression model. 
er for the difference between predicted and measured 6MWT distance using Ulrich equation.

\section{Discussion}

The 6MWT is a simple method to estimate the sub-maximal exercise capacity. It is well tolerated by patients with chronic diseases [1]. In our study, 6MWD was shorter in subjects with cystic fibrosis than the healthy predicted distance. This data is confirmed by some studies but few of those have reported mean ages close to our sample (mean age: $8.7 \pm 1.6$ years).

Pereira et al. [9] compare patients with cystic fibrosis and healthy individuals (mean age: 12.2 \pm 4.3 ). 6MWD was significantly shorter in the cystic fibrosis group than in the control group (547.2 $\pm 80.6 \mathrm{~m}$ vs $610.3 \pm 53.4 \mathrm{~m}$, respectively; $\mathrm{p}<0.0001)$. Gruber et al. [22] administered 6MWT to 286 patients with CF, age range 6-18 years (11.8 \pm 3.4 years). Children with $C F$ had a lower walk distance in 6MWT $(\mathrm{p}<0.05)$ compared to healthy. Other groups of authors [1,23-24] who also administered 6MWT to adolescent and adults with cystic fibrosis reported differences between the $\mathrm{CF}$ group and the control group.

In the present study, boys and girls covered similar distances in both groups, a finding that has been documented in other studies $[9,15,25]$. This difference compared to older subject studies [16,26] is easily explained by the prepubertal age of the subjects studied. As described by Pereira et al. [9] in our sample there were no episodes of desaturation as opposed to studies performed with older patients [27-28]. According to Lima et al. [8], we observed that the 6MWD does not correlate with the reduction of $\mathrm{FEV}_{1}$. However, FEV $\mathrm{F}_{1}$ has demonstrated not to be an early and sensitive indicator of abnormal lung function and is also not related with changes in other clinical data such as lung clearance index or computed tomography [29].

We observed a statistically significant difference in 6MWT distance between those who practice sports and those who do not. This regard is important because it shows that training changes physical performance, even in children with $\mathrm{CF}$ in this particular age. This data has also been reported by Grubrer et al. [22]. They reported that compared to healthy children, patients with CF had a lower walk distance in 6MWT but after training 6MWD increased in all sample in particularly in 6-10 aged children; after training 6MWD CF versus healthy children was not statistically significant difference $(p>0.05)$. Many studies [3-6,22,24] have shown that exercise capacity in CF patients is related to mortality, therefore we emphasize the importance of training evaluation and planning.

Several studies $[14,15,24,30]$ indeed suggested that $6 \mathrm{MWD}$ may be influenced by lifestyle. Saad et al. [30] reported this phenomenon too but avoided to include it into a regression model because the level of physical activity is difficult to assess and quantify. In our sample subjects with a $\mathrm{FEV}_{1}$ below of their LLN walked more meters than those who had a higher $\mathrm{FEV}_{1}$, otherwise than reported in other studies [8]. This can be explained because, in the sample studied, children with a lower $\mathrm{FEV}_{1}$ practiced more sports than the others $(p<0.001)$. Probably as a result of care team's increased attention to them, especially for the practice of physical activity. It should also be considered that other factors may influence the performance of 6MWT and spirometry in this age group, such as motivation and familiarity with the test. It is also important to consider that Bland-Altman plots quantify the bias and range of agreement, within which $95 \%$ of the differences between one measurement and the other. Therefore, those plots should be analyzed considering that the limit of maximum acceptable differences reported by literature is 45 meters. With this definition a pri- ori it is clear that all predicted models exceed this limit widely.

Our study has some limitations. Enrollment was carried out by selecting the subjects attending the CF centers in a given period of time. Therefore, there was the risk to selected patients not completely representative of the entire CF population. Since tests were carried out in different centers, by different operators, there may be variability between the tools used for the evaluations. A limit of the present study is that there is no consensus regarding which published equations should be used for predicting normal values for the 6MWD in children. In this study was selected Vandoni's reference because the population was the most similar to ours for ethnic characteristics. Moreover, data show wide heteroskedasticity, the models from which predicted values were obtained do not allow to describe the wide variability and variance of cystic fibrosis's population. This suggests the inclusion of other parameters in the model such as physical activity or hearth rate difference.

\section{Conclusions}

In our sample, functional performance at 6MWT was poorer in cystic fibrosis patients than the predicted distance, but there is no correlation between $\mathrm{FEV}_{1}$, FVC, use of antibiotics, day of hospitalization, microbiological status and walk distance in meters. However, it has been established the correlation with the amount of physical activity and 6MWD. The ease and simplicity administration of this low-cost test in this age group is confirmed.

\section{Acknowledgments}

The authors would like to thank the respiratory physiotherapist team of Physical Medicine and Rehabilitation Department and the Interdisciplinary Team of the Cystic Fibrosis Center, Meyer Children's Hospital, Florence, Italy. We also thank all our little patients who have given their contribution.

\section{References}

1. Ziegler B, Rovedder PM, Lukrafka JL, et al. Submaximal exercise capacity in adolescent and adult patients with cystic fibrosis. J Bras Pneumol 2007;33:263-9.

2. Sahlberg ME, Svantesson U, Thomas EM, Strandvik B. Muscular strength and function in patients with cystic fibrosis. Chest 2005;127:1587-92.

3. Peterson ML, Jacobs DR Jr, Milla CE. Longitudinal changes in growth parameters are correlated with changes in pulmonary function in children with cystic fibrosis. Pediatrics 2003;112:588-92.

4. Arikan H, Yatar L, Calik-Kutukcu E, et al. A comparison of respiratory and peripheral muscle strength, functional exercise capacity, activities of daily living and physical fitness in patients with cystic fibrosis and healthy subjects. Res Developl Disabil 2015;45-46:147-56.

5. Orenstein DM, Higgins LW. Update on the role of exercise in cystic fibrosis. Curr Opin Pulm Med 2005;11:519-23.

6. Schneiderman-Walker J, Pollock SL, Corey M, et al. A randomized controlled trial of a 3-year home exercise program in cystic fibrosis. J Pediatr 2000;136:304-10. 
7. Coelho CC, Aquino Eda S, de Almeida DC, et al. Comparative analysis and reproducibility of the modified shuttle walk test in normal children and in children with cystic fibrosis. J Bras Pneumol 2007;33:168-74.

8. Lima C, de Andrade A, Campos S, et al. Six-minute walk test as a determinant of the functional capacity of children and adolescents with cystic fibrosis: A systematic review. Respir Med 2018; $137: 83-8$.

9. Pereira FM, Ribeiro MÂ, Ribeiro AF, et al. Functional performance on the six-minute walk test in patients with cystic fibrosis. J Bras Pneumol 2011;37:735-44.

10. Hassan J, van der Net J, Helders PJ, et al. Six-minute walk test in children with chronic conditions. Br J Sports Med 2010;44:270-4.

11. Gulmans VA, van Veldhoven NH, de Meer K, Helders PJ. The six-minute walking test in children with cystic fibrosis: reliability and validity. Pediatr Pulmonol 1996;22:85-9.

12. Cunha MT, Rozov T, Caitano de Olivera R, Jardim JR. Six minutes walk test in children and adolescents with cystic fibrosis. Pediatr Pulmonol 2006;41:618-22.

13. Vandoni M, Correale L, Puci MV, et al. Six minute walk distance and reference values in healthy Italian children: A crosssectional study. PLoS One 2018;13:e0205792.

14. Geiger R, Strasak A, Treml B, et al. Six-minute walk test in children and adolescents. J Pediatr 2007;150:395-9.

15. Lammers AE, Hislop AA, Flynn Y, Haworth SG. The 6-minute walk test: normal values for children of 4-11 years of age. Arch Dis Child 2008;93:464-8.

16. Ulrich S, Hildenbrand FF, Treder U, et al. Reference values for the 6-minute walk test in healthy children and adolescents in Switzerland. BMC Pulm Med 2013;13:49.

17. Farrell PM, White TB, Ren CL, et al. Diagnosis of cystic fibrosis: Consensus guidelines from the Cystic Fibrosis Foundation. J Pediatr 2017;184:243.

18. ATS Committee on Proficiency Standards for Clinical Pulmonary Function Laboratories. ATS Statement. Guidelines for the Six-Minute Walk Test. Am J Respir Crit Care Med 2002;166:111-7. Erratum in ATS Statement: Guidelines for the Six-Minute Walk Test. Am J Respir Crit Care Med 2016;193:1185.
19. European Cystic Fibrosis Society. ECFS Patient Registry. Annual Data Report 2017 daata. Accessed ON: 22 December 2020. Available from: https://www.ecfs.eu/sites/default/files/ general-content-images/working-groups/ecfs-patient-registry/ECFSPR_Report2017_v1.3.pdf

20. Quanjer PH, Stanojevic S, Cole TJ, et al. Multi-ethnic reference values for spirometry for the 3-95-yr age range: the global lung function 2012 equations the ERS Global Lung Function Initiative. Eur Respir J 2012;40;1324-43.

21. Flume PA, O'Sullivan BP, Robinson KA, et al Cystic fibrosis pulmonary guidelines: chronic medications for maintenance of lung health. Am J Respir Crit Care Med 2007;176:957-69.

22. Gruber W, Orenstein DM, Braumann KM, Huls G. Healthrelated fitness and trainability in children with cystic fibrosis. Pediatr Pulmonol 2008;43:953-64.

23. Lesser DJ, Fleming MM, Maher CA, et al. Does the 6-min walk test correlate with the exercise stress test in children? Pediatr Pulmonol 2010;45:135-40.

24. Troosters T, Langer D, Vrijsen B, et al. Skeletal muscle weakness, exercise tolerance and physical activity in adults with cystic fibrosis. Eur Respir J 2009;33:99-106.

25. Priesnitz CV, Rodrigues GH, Stumpf da Silva C, et al. Reference values for the 6-min walk test in healthy children aged 6-12 years. Pediatr Pulmonol 2009;44:1174-9.

26. Troosters T, Gosselink R, Decramer M. Six minute walking distance in healthy elderly subjects. Eur Respir J 1999;14:270-4.

27. Chetta A, Pisi G, Zanini A, et al. Six-minute walking test in cystic fibrosis adults with mild to moderate lung disease: comparison to healthy subjects. Respir Med 2001;95:986-91.

28. Gomez Punter RM, Girón Moreno RM, Vázquez Espinosa E, et al. Desaturations during 6-minute walk test and predicting nocturnal desaturations in adult subjects with cystic fibrosis. Respir Care 2019;64:48-54.

29. Rayment JH, Stanojevic S, Davis SD, et al. Lung clearance index to monitor treatment response in pulmonary exacerbations in preschool children with cystic fibrosis. Thorax 2018;73:451-8.

30. Saad HB, Prefaut C, Missaoui R, et al. Reference equation for 6-min walk distance in healthy North African children 6-16 years old. Pediatr Pulmonol 2009;44:316-24. 